\title{
DECORAÇÃO E AMBIENTAÇÃO NA ESCOLA DE EDUCAÇÃO INFANTIL
}

\author{
Renata Pavesi Cocito, Fátima Dias Gomes Marin
}

Universidade Estadual Paulista - UNESP, Presidente Prudente, SP. E-mail:renatapavesi@hotmail.com

\section{RESUMO}

O artigo é um recorte da dissertação de mestrado intitulada "Do espaço ao lugar: contribuições para a organização dos espaços de bebês e crianças pequenas", defendida em maio de 2017 e vinculada ao PPGE - Programa de Pós-graduação em Educação da UNESP Universidade Estadual Paulista campus de Presidente Prudente/SP. O objetivo do artigo é apresentar a decoração e a ambientação dos espaços destinados a Educação Infantil como um elemento essencial em sua organização. Utilizamos a pesquisa qualitativa do tipo bibliográfica para a composição dos estudos. A decoração nas instituições de Educação Infantil vai além do ornamento dos espaços e assume a roupagem de ambientação. A ambientação contribui com a construção da identidade do espaço e daqueles que o vivenciam e, ainda, corrobora no processo de construção de um ambiente acolhedor e aconchegante, favorecendo o processo de pertencimento a esse espaço e a constituição do espaço como um lugar, permeado pelos afetos.

Palavras-chave: Educação Infantil - espaço - organização espacial - ambientação - decoração

\section{DECORATION AND AMBIANCE IN SCHOOL OF CHILDREN EDUCATION}

\begin{abstract}
The article is a cut of the dissertation entitled "From space to place: contributions to the organization of spaces for babies and small children", defended in May 2017 and linked to the PPGE - Graduate Program in Education of UNESP State University Paulista campus of Presidente Prudente / SP. The purpose of this article is to present the decoration and the ambience of spaces for Early Childhood Education as an essential element in its organization. We used the qualitative research of the bibliographic type for the composition of the studies. The decoration in the Institutions of Infantile Education goes beyond the ornament of the spaces and assumes the atmosphere dressing. The environment contributes to the construction of the identity of the space and of those who experience it, and also corroborates in the process of building a warm and welcoming environment, favoring the process of belonging to this space and the constitution of space as a place, permeated by affections.
\end{abstract}

Keywords: Child Education - space - spatial organization - ambiance - decoration 


\section{INTRODUÇÃO}

O artigo é um recorte da dissertação de mestrado intitulada "Do espaço ao lugar: contribuições para a organização dos espaços de bebês e crianças pequenas", defendida em maio de 2017. A pesquisa está vinculada ao PPGE - Programa de Pós-graduação em Educação da UNESP Universidade Estadual Paulista campus de Presidente Prudente/SP. Na dissertação o espaço educacional é concebido como um elemento curricular, um "espaço educador". A organização do espaço físico foi trabalhada considerando os materiais, o mobiliário e a decoração como elementos essenciais para sua composição, conforme sugere Forneiro (1998). O conceito de ambiente é apresentado como a junção entre espaço físico e as relações (FORNEIRO, 1998) e o lugar é considerado como o espaço dotado de valor, construído de maneira singular por meio das experiências vividas por cada sujeito em determinado espaço (TUAN, 2012).

A decoração, em nossa perspectiva de estudo, tem como função dar visibilidade as produções, necessidades e preferências daqueles que habitam e vivenciam o espaço da escola de Educação Infantil. Portanto, a decoração não assume apenas a função de adornar o espaço físico da escola. Assim, além da decoração, assumida em nossa pesquisa e oriunda das ideias de Forneiro (1998), discutimos a terminologia ambientação incutida. Quando falamos em ambientação estamos nos referindo aos itens materiais que compõem os espaços e que colaboram com o estabelecimento das relações entre a criança e o espaço. Consideramos que este aspecto precisa ser explorado, haja vista que contribui para a qualificação do espaço e para a ação docente com relação a sua organização.

Desta maneira, temos como objetivo apresentar a decoração e a ambientação dos espaços destinados a Educação Infantil como um elemento essencial em sua organização. Consideramos que a composição dos espaços deve ser edificada com intencionalidade, estar alinhada com a proposta pedagógica da instituição e o ter conexões com os fazeres de adultos e crianças, bem como com a comunidade escolar.

\section{METODOLOGIA}

Utilizamos a pesquisa qualitativa do tipo bibliográfica para a composição dos estudos. Nos embasamos em autores que abordam a organização dos espaços na Educação Infantil e que consideram a decoração como um elemento integrador na composição de um espaço educador. Destacamos as ideias de: Forneiro (1998), Cunha (2005), Blower (2008), Barbieri (2012), Tuan (2012), Ceppi e Zini (2013) e Vecchi (2017).

\section{RESULTADOS}

Quando decoramos pensamos no posicionamento de objetos, em suas cores, formas e na maneira como interagem entre si considerando que devem gerar uma composição harmônica. Essa composição é variável, se modifica de uma cultura para outra, de um país para outro, de uma escola para outra. Embora as instituições de Educação Infantil tenham assumido no decorrer dos anos alguns elementos que as caracterizam, criando um estereótipo de prédio/edificação para a educação e cuidados de crianças, cito: presença de cores vibrantes nas fachadas e de personagens midiáticos no interior das salas, muros, paredes, cartazes, por exemplo, não é possível (nem desejável) termos uma padronização na decoração. Cunha ao observar e analisar a composição dos espaços de Educação Infantil evidencia que: 
Na maioria das escolas, independentemente da formação das educadoras, da proposta pedagógica das escolas, das características socioeconômicas das comunidades e da própria configuração do espaço arquitetônico, as ambiências eram semelhantes, os elementos se repetiam, se multiplicavam, como se houvesse uma matriz geradora para a educação infantil (CUNHA, 2005, p.173).

Acreditamos que ainda exista uma forte compreensão de que para ser uma "autêntica" escola de educação e cuidados de bebês e crianças pequenas é preciso que seja construída, obrigatoriamente, com esses elementos estereotipados. Replicando assim maneiras de se organizar os espaços sem reflexão sobre a prática pedagógica e sem questionar se tais necessidades realmente precisam ser atendidas.

As imagens dos cenários, por atravessarem tempos e contextos, tornam-se repetitivas, e assim são aceitas e naturalizadas nos contextos educacionais. As crianças não se surpreendem com o que vêem, as educadoras colocam ano a ano suas decorações nas paredes, escolhem um personagem feminino para identificar as meninas, um masculino para os meninos, uma imagem para lembrar que as crianças devem escovar os dentes, dormir, não morder, comer, obedecer às combinações, temer. Nessa sucessão de imagens semelhantes, o espaço para o estranhamento, para interrogações e problematizações, é mínimo. O olhar conformado e que se constitui nesses locais impede o trânsito para outros modos de ver. Educadoras e crianças se acostumam com a regularidade de tais imagens. As semelhanças definem o costumeiro, o aceito, o esperado. Há poucos elementos que indicam reelaboração, marcas pessoais, surpresas, emoções. São escassas as singularidades que emergem em meio a estas imagens; quando elas surgem, são consideradas fora dos padrões. As escolas em geral, e em especial as escolas infantis, poderiam realizar um trabalho na contracorrente das pedagogias da visualidade que circula nos mais variados meios, no sentido de pensar estratégias e viabilizar ações para que o olhar possa ser provocado, mobilizado, surpreendido, tornando-se crítico e sensível ao mundo, a outras imagens, aos outros (CUNHA, 2005, p.182-183).

Neste contexto, destacamos a expressão "decorações desnecessárias" utilizadas por Ceppi e Zini (2013) quando focam a necessidade de cores neutras e harmoniosas e a presença de elementos que realmente tenham relação com as vivências institucionais. Consideramos como desnecessárias aquelas decorações que não possuem autoria, ou seja, não foi gestada no interior da instituição com sentido e significado; ou que estejam descontextualizadas e não relacionadas aos propósitos e necessidades da instituição. Forneiro (1998, p.239) enfatiza que:

A sala de aula pode estar decorada de tal modo que eduque a sensibilidade estética infantil. A decoração transforma-se, assim, em conteúdo de aprendizagem: a harmonia das cores, a apresentação estética dos trabalhos, etc.

A decoração nas instituições de Educação Infantil vai além do simples ornamento dos espaços e assume a roupagem de ambientação. Nesta perspectiva, a decoração privilegia as produções das crianças e da comunidade escolar, trazendo elementos da cultura local, regional e mundial, englobando elementos pertencentes a história da instituição e dos sujeitos históricos que contribuíram com a trajetória da mesma. De acordo com Forneiro (1998, p.240) "a escola deve ser o lugar privilegiado no qual se tem acesso à cultura. O cenário formador onde a série de hábitos, atitudes, competências, conhecimentos são abordados de uma maneira explícita".

A vinculação dos objetos com os sujeitos, a instituição e sua história contribuem para que o ambiente seja composto por elementos que se conectam, se tornando significativo e acolhedor. Vecchi (2017) coloca que a relação entre o sujeito e as estruturas resulta na dimensão estética do ambiente, e evidencia: "no âmbito educativo, merecia uma profunda reflexão, e estou certa de que a 
sua presença consciente nas escolas e na educação faria elevar tanto a qualidade das relações como o contexto quanto a dos processos de aprendizagem" (VECCHI, 2017, p.28).

Rabitti (1999, p.152-153) chama a atenção para a composição do "ambiente como memória" e destaca que "o material exposto deve 'comunicar' a crianças e adultos (educadores, familiares e visitantes) o que se está fazendo na escola e como se está operando". A mesma autora evidencia que além de evocar memórias "[...] o cuidado com o qual os trabalhos das crianças são expostos possui também outra importância: valorizar a própria atividade das crianças e criar um ambiente agradável e 'belo'".

\section{DISCUSSÃO}

O espaço deve refletir a vida da escola, os objetos presentes devem ter relação com a cultura infantil e com a cultura da instituição. Ceppi e Zini (2013, p.74) consideram a parede uma tela que pode ser pintada e transformada, a parede é parte integrante da composição do ambiente:

[...] é o plano de fundo para a comunicação, documentação, produtos e objetos, devem ser cromaticamente hospitaleiras; isto é; é melhor ter uma única cor que age como base e sustenta as imagens penduradas nas paredes e que dá ao espaço um elemento unificador.

Nesta mesma perspectiva Blower (2008, p.83) evidencia a necessidade de se estabelecer equilíbrio na composição do cenário visual dos espaços que são utilizados pelas crianças e assevera:

Sobre percepção visual, as salas de atividades com excessos de ilustrações, enfeites e gravuras penduradas nas paredes ou cores berrantes promovem uma estimulação visual excessiva, podendo levar a criança à distração, causar poluição visual dificultando a identificação dos valores estéticos pessoais, impedindo a apropriação do ambiente e conseqüente construção do "lugar".

Desta forma, o espaço pode ser interpretado, desde que estruturado tem a capacidade de se expressar, as paredes e os elementos que nela são expostos transmitem sensações, evocam ideias, narram histórias. Sobre este tipo de exposição Barbieri $(2012$, p.57) orienta que:

Cada vez que compartilhamos a produção das crianças, isso precisa ser exposto com rigor estético, considerando as necessidades dos trabalhos a serem mostrados - usar um painel limpo, pendurar os trabalhos com harmonia, distribuídos para que não fiquem entulhados. $A$ exposição deve mostrar o cuidado do professor com a produção de seus alunos. A valorização do processo de criação deve acompanhar a exposição. [...] A produção estética das crianças precisa ocupar a escola, de forma a permitir que elas olhem o que fizeram, vejam a produção uma das outras. Os trabalhos se tornam criadores de perspectivas porque as crianças podem olhar para as produções, discutir, conversar e aprender com isso.

A presença das produções das crianças confere originalidade ao espaço, Forneiro (1998) coloca a personalização dos espaços como um elemento decorativo importante que possibilita a reflexão sobre a identidade. A autora sugere que "devemos reservar lugares para colocar os trabalhos das crianças e cuidar de sua apresentação a fim de que realce o seu valor estético e afetivo" (FORNEIRO, 1998, p.261).

Baker et. al. (2012, p.128) apresenta elementos que compõe a decoração de um espaço para Educação Infantil:

Colocamos objetos intrigantes, como cerâmica, fotografias e trabalhos têxteis ao redor da sala para convidar ao estudo, provocar interesse e aumentar a qualidade do espaço. A maior parte do espaço para exposição ficava reservada para o trabalho das crianças e as páginas e painéis de documentação que aprendemos lentamente a criar. 
A personalização do espaço pode se dar de outras formas, não apenas com a exposição de materiais das crianças, mas por meio de exposição de fotografias das crianças, pais, familiares e da equipe escolar, a identificação de alguns pertences com o nome das crianças e do professor. Sobre a possibilidade das crianças terem objetos que os represente dentro do espaço da escola Calmels (2011, p. 59-60) considera que:

Sería beneficiosa para el niño la posibilidad de tener un espacio en la escuela para sus objetos, espacio que puede ser um armario, cajón, caja. El niño tendria así uma representación de la escuela, no sólo como un lugar de tránsito, sino de lugar donde sus cosas permanecen más allá de su presencia. [...] em cada escuela habría um pedazo de território personal donde se alojarían los materiales que participan del aprendizage.

Sobre a presença das fotografias e outros registros Baker et. al. (2012, p.128) descreve:

Fotografias das crianças e suas famílias, uma declaração de boas-vindas, e uma descrição de nossa filosofia acompanham o poema "As cem linguagens das crianças" em quadros de avisos em cada sala. Esperamos que isso convidasse e estimulasse o desenvolvimento de relacionamentos duradouros de aprendizagem com nossas crianças e famílias e fosse a declaração clara de nossos valores e comprometimento.

Portanto, quando organizamos um espaço de Educação Infantil e nele colocamos elementos que não possuem sentido pedagógico e que, por este fato, não contribuem com a construção da identidade institucional e que não representa aqueles que frequentam a instituição, estamos apenas decorando o espaço.

Por outro lado, quando a decoração de uma instituição é composta e organizada considerando as especificidades locais e da comunidade escolar e, acima de tudo, quando favorece a conexão do sujeito, adulto ou criança, com o espaço/ambiente, a chamamos de ambientação. Ela contribui com a construção da identidade do espaço e daqueles que o vivenciam e, ainda, corrobora no processo de construção de um ambiente acolhedor e aconchegante, favorecendo o processo de pertencimento a esse espaço e a constituição do espaço como um lugar, permeado pelos afetos. A ambientação perpassa pela reflexão dos fazeres pedagógicos.

\section{CONCLUSÕES}

A leitura do espaço é um componente importante para a compreensão de seu sentido e significado para uma instituição. É uma leitura de práticas, desejos, intencionalidades, objetivos e concepções dos sujeitos de uma instituição que ficam disponibilizadas pelos diferentes espaços; sua leitura só é possível com o olhar atento.

O espaço revela, fala, comunica. Os objetos, a mobília, os materiais, a decoração, os detalhes contidos em cada canto da instituição, mesmo que sem a presença física de crianças e adultos, revelam as intencionalidades e prioridades da instituição - tem uma função educativa.

As reflexões sobre decoração e ambientação indicam que a diferenciação entre as terminologias, está no processo de construção. Ambientação denota envolvimento com o objeto utilizado para compor a organização de determinado espaço físico. A decoração está relacionada a ação mecânica manifestada pelo desejo e gosto pessoal de um sujeito, geralmente o professor, para "embelezar" o espaço da sala. 
Consideramos urgente despender um olhar cuidadoso e responsivo em relação a decoração e ambientação das instituições de Educação Infantil, as crianças quando se sentem representadas no ambiente tem a possibilidade de se sentirem pertencentes ao espaço institucional e assim estabelecer laços afetivos com o mesmo.

\section{REFERÊNCIAS}

BAKER, P. M. Vozes do ateliê: histórias de transformação. In: GANDINI, L et. al. (ogrs.) O papel do ateliê na Educação Infantil - a inspiração de Reggio Emilia. Porto Alegre: Ed. Penso, 2012. P. 123-152.

BARBIERI, S. Interações: onde está a arte na infância? São Paulo: Blucher, 2012.

BLOWER, H.C.S. O lugar do ambiente na educação infantil: estudo de caso na creche doutor Paulo Niemeyer. 2008. Disponível em: <http://www.dominiopublico.gov.br/download/texto/cp049183.pdf> Acesso em: 23 de outubro de 2014.

BLOWER, H.S.; AZEVEDO, G.A.N.; VASCONCELLOS, V.M.R. O lugar do ambiente na Educação Infantil: APO na creche Paulo Niemeyer. Grupo de Pesquisa: Ambiente-Educação (GAE) p. 1 - 16. 2008. Disponível em: <http://www.fau.ufri.br/prolugar/assets/trab2 o-lugar ambiente.pdf> Acesso em: 15 de março de 2016.

CALMELS. D. Espacio habitado: en la vida cotidiana y la practica professional. 1a ed. Homo Sapiens Ediciones, 2011.

CEPPI, G.; ZINI M. (Org.). Crianças, espaços e relações: como projetar ambientes para a Educação Infantil. Porto alegre: Penso, 2013.

COCITO, R.P. Do espaço ao lugar: contribuições para a organização dos espaços para bebês e crianças pequenas. 2017. 185f. Dissertação (Mestrado em Educação) - Faculdade de Ciências e Tecnologia, Universidade Estadual Paulista, Presidente Prudente. Disponível em: https://repositorio.unesp.br/handle/11449/151013 Acesso em: 17/01/2018

CUNHA, S.R.V. Cenários da Educação Infantil. Educação e Realidade. 30(2):165 - 185, jul/dez 2005. FORNEIRO, L.I. A organização dos espaços na educação infantil. In: ZABALZA, M. A. Qualidade em Educação Infantil/ tradução Beatriz Affonso Neves. Porto Alegre: Artmed, 1998.

HORN, M.G.S. Sabores, cores, sons, aromas. A organização dos espaços na educação infantil. Porto Alegre: Artmed, 2004.

OLIVEIRA et. al. (org.) O trabalho do professor na Educação Infantil. São Paulo: Ed. Biruta, 2012.

RABITTI, G. À procura da dimensão perdida: uma escola de infância de Reggio Emília. Artmed: Porto Alegre, 1999.

TUAN, Y. Topofilia: um estudo da percepção, atitudes e valores do meio ambiente. Tradução de Lívia de Oliveira. Londrina: EDUEL, 2012. 
VECCHI, V. Arte e criatividade em Reggio Emilia: explorando o papel e a potencialidade do ateliê da primeira infância. Coleção Reggio Emília. Ed. Phorte, 2017. 